\title{
PARTICIPATION IN PHARMACEUTICAL COSTS AND SENIORS' ACCESS TO MEDICINES IN THE CZECH REPUBLIC
}

\author{
Jana Davidová, Natasa Ivanovic, Lenka Práznovcová \\ Department of Social and Clinical Pharmacy, Faculty of Pharmacy in Hradec Králové, Charles University in Prague, Czech Republic
}

\section{SUMMARY}

Objectives: Analysis of participation in drug costs by seniors in the Czech Republic in connection with seniors' access to pharmacotherapy.

Materials and methods: Quota-sampled guided interview with 450 respondents visiting pharmacy; ratio of men and women approximately 1:2; age over 60 years; 3 regions of the Czech Republic.

Results: Respondent's income was retirement pension in $80 \%$. More than $55 \%$ of respondents did not reach the official state average. Respondents used altogether 1,650 medicines on physician's prescription in the last four weeks. Overall co-payment for medicines was 38,778 CZK, i.e. 86 CZK per patient. Only $27 \%$ of respondents used fully reimbursed products. Respondents used together 273 OTC drugs (over-the-counter drugs, e.g. non prescription drugs) in value of $16,540 \mathrm{CZK}$, i.e. $37 \mathrm{CZK}$ per patient. Average respondent spent on medicines $123 \mathrm{CZK}$ in the last four weeks, i.e. $1.5 \%$ of the official state average income. There were respondents, about 10\%, searching for the level of co-payment in several pharmacies and more than $8 \%$ of respondents had to refuse dispensation of medicines due to co-payment.

Conclusions: Our study demonstrates that there are patients who may fail to gain access to medication due to co-payment in the Czech Republic. The financial participation in health care costs is generally low in the Czech Republic ( $8.8 \%$ of total health expenditures) but there were differences in co-payment levels in patients ranging from $1 \mathrm{CZK}$ to thousands CZK.

In our opinion problem might be in the absence of any instrument limiting the highest individual participation as it is for example in 12-month period in Sweden. In our study co-payments were lower in smaller communities that may be due to better communication between physicians and patients or physicians and pharmacists. We found a critical ethical problem in different levels of co-payment of concrete product.

Key words: seniors, Czech Republic, pharmaceutical costs, participation in costs, co-payment, access to pharmacotherapy

Address for correspondence: J. Davidová, Gdaňská 333, 18100 Praha 8. E-mail: davidova@faf.cuni.cz

\section{INTRODUCTION}

Pharmaceutical expenditures represent continually substantial part of resources spent on health care in the Czech Republic. From 1990 till 2004 total pharmaceutical expenditures (TPhE) amounted to 25 to $28 \%$ of total health expenditures (THE) (1, 2). In this respect, the Czech Republic significantly outruns an average of West European countries, where TPhE usually amount to $14 \%$ of THE $(3,4)$. More than $20 \%$ of THE is usually spent on pharmaceuticals in other post-socialistic countries (Bulgaria, former Jugoslavia) (5).

In 2004, THE amounted to 198 Mld. CZK (1 US\$ $=22.4$ CZK or $1 €=27.8 \mathrm{CZK}$ ), which was $7.16 \%$ of Gross Domestic Product (GDP). Public and private resources covered $91.2 \%$ and $8.8 \%$, respectively.

Private payments occur mainly in the category of medicines in the Czech Republic. Total pharmaceutical expenditures were 52.5 Mld. CZK in 2003 and insurance funds (i.e. public resources) covered $36 \mathrm{Mld}$. CZK from this amount (6). The rest was covered by payments for over-the-counter (OTC, i.e. non-prescription) pharmaceuticals and patients' co-payments for medicines prescribed by a physician.

As to the structure of those expenditures in the society, in an average household a person spent in 2004 on health and pharmaceuticals 144 and 117 CZK (i.e. $1.52 \%$ and 1.24\%) of his/her income, respectively. In the households of seniors a person spent in 2004212 and 161 CZK (i.e. $2.58 \%$ and 1.61\%), respectively (7).

The Act on Public Health Insurance (8) clusters all reimbursed medicines into 300 groups based upon their therapeutic classification and administration route and it explicitly specifies that in each group at least one medicinal product shall be fully reimbursed. In this way, there should always be a fully reimbursed alternative to choose by the physician and the patient.

But the definition of groups appears problematic and it seems to be not sufficient for all medical situations. There are no official incentives for prescribing doctors to choose fully reimbursed or cheaper or generic products in the Czech Republic. Generic substitution in pharmacy has not been introduced.

In the first quarter 2004, there were 8,845 pharmaceutical products on the market in the Czech Republic (9). Only $21.71 \%$ of 
them were defined as fully reimbursed. However, the real number of fully reimbursed products on the market might be higher since this methodology operates only with the maximum prices set by Ministry of Finance.

In 2004 each citizen of the Czech Republic received 9.23 physician's prescriptions for pharmaceuticals (10) and the average co-payment per prescription was 54 CZK. Total consumption of pharmaceuticals amounted to 329 Mil. packs.

Unfortunately, there is no publicly available information concerning structure of pharmaceutical consumption and expenditures of different age or social groups in the Czech Republic. The only information available is on total health expenditures per capita (18,000 CZK and 1,302 US\$ PPP in 2003, respectively) $(6,11)$ and per insured person in different age categories (with an average of 14,600 CZK in 2004) (10). Health expenditures per insured person significantly increase in patients aged over 55 years. From 60 years of age, total health expenditures amount to more than double of the average.

Our study aims to describe seniors' participation in expenditures on prescribed and OTC pharmaceuticals in the Czech Republic. Further, it focuses on influence of these costs on seniors' access to pharmacotherapy.

\section{MATERIALS AND METHODS}

Guided interview was chosen as a method of investigation. Our three inquirers had a schema available with 22 questions. Several questions were closed (basic demographic data) and in the other questions respondents were asked to choose one of alternative answers.

Inclusion criteria were: visit at a pharmacy for prescribed pharmaceuticals, age 60 and older. Respondents were included into sample by quota sampling, i.e. until desired number of respondents was reached. Men and women were included separately so the final ratio in the sample reached 1:2 (corresponding to distribution of sex in these age categories).

Main exclusion criterion was a stay in pensioners' home, where personnel dispense medication. Further, persons, who were not willing or able to answer questions about their income and/or spending, were excluded from the sample.

Respondents were searched for in three regions of the Czech Republic with different socio-economic structure.

Data collection was provided from May 2004 till December 2004. In this time period, reimbursement of pharmaceuticals was defined by only one version of Decree of Ministry of Health No. 57/1997 as amended (12), that lists fully reimbursed pharmaceuticals and levels of reimbursement of active substances. Code List of Medicinal Products of the General Health Insurance Fund of the Czech Republic (GHIF CR) version 520 (9) in force from 1.5.2004 was used to analyse received data.

Microsoft Office programmes Excell and Access and Paradox program were used for statistic analysis of received data.

\section{RESULTS}

Set of respondents amounted to 450 persons aged over 60 years, who visited pharmacy to obtain prescribed medication. Men : women ratio was approximately 1:2. Most of respondents (60\%) lived in households with their partners. Most common type of respondents' income was retirement pension (80\%). In more than $55 \%$ of respondents it amounted to 5,001 up to 7,499 CZK. Those respondents didn't reach the official state average income.

Respondents consumed 1,650 pharmaceuticals prescribed by physician in the last 4 weeks. Each respondent consumed approximately 3.70 pharmaceuticals.

Respondents consumed 284 OTC pharmaceuticals, i.e. each of them approx. 0.63.

An average co-payment for prescribed pharmaceuticals amounted to $86 \mathrm{CZK}$ per respondent or $23.50 \mathrm{CZK}$ per product (1 US\$ $=22.4 \mathrm{CZK}$ or $1 €=27.8 \mathrm{CZK}$ ). Respondents spent together $38,778 \mathrm{CZK}$ on prescribed pharmaceuticals in the last 4 weeks. Respondents spent 16,540 CZK on OTC drugs. An average cost of OTC drugs was $36.80 \mathrm{CZK}$ per respondent or $58 \mathrm{CZK}$ per product in last 4 weeks.

Number of respondents using only fully reimbursed pharmaceuticals was 117 (i.e. 26\%). Ratio of fully reimbursed products used by respondents was $44.30 \%$.

Average respondents spent on medicines $123 \mathrm{CZK}$ in the last four weeks, i.e. $1.5 \%$ of the official state average income. There were respondents, about $10 \%$ of them, searching for the level of co-payment in several pharmacies and $8.6 \%$ of respondents, who had to refuse dispensation of medicines due to co-payment.

\section{DISCUSSION}

According to official statistic data seniors spend about $2.5 \%$ of their income on health, with pharmaceuticals share of about $1.5 \%$ (7). This number doesn't seem too high. But our results show that more than $55 \%$ of respondents may not reach the official average income. Further, there were $26 \%$ of respondents in our research group, who used only fully reimbursed medicines. Intentionally, we didn't include seniors who didn't consume any medicines. So those who participated on cost of their medicines spent in average 209 CZK i.e. $2.5 \%$ of their income only on medicines. Maximal amount paid during last four weeks was 3,000 CZK by a respondent to whom 16 different medicinal products were prescribed. This was a great exception and was excluded from statistical analysis.

Results of our study may vary from official data mainly due to excluding respondents, who didn't use any medicines and persons who were not able to take care about obtaining medications themselves anymore. Respondents, who were not willing to or not able to answer questions about their income and spending on medication, were excluded, too.

Further, we understand the limitations of sociological methods we used. We worked with respondents 60 years old and older so possible deviation may occur due to worse memory of exact spending and possible rounding.

Strong points of our study are that interviews were carried out in pharmacy and so in most cases it was possible to identify the exact medicinal products used by respondents and identify those products by a registration code. Pharmacy setting enabled to eliminate doubling of spending when more packs of a product were prescribed, too. Accordingly expenditures correspond in large scale to a real four-week consumption of medication. 
Some respondents (about 10\%) searched for level of co-payments in different pharmacies to achieve the lowest participation. However, in deeper analysis we found out, that those respondents lived mainly in the capital, were they could visit many more pharmacies.

Further, our study shows great differences in level of co-payment of concrete medicinal product depending mainly on the size of the city or town and on the size and type of the pharmacy the respondents visited. Pharmacies with great returns may lower their part of trade margin and in this way lower possible co-payment to attract more customers.

There were respondents in our research group (about 8.6\%), who were forced to reject the dispensation of their medicines due to the level of co-payment. The situation occurred mainly in respondents using more than one medicinal product and in some respondents, to whom medication for more months was prescribed.

Seniors are particularly vulnerable population concerning quality of life, defined as complex concept of person's physical health, psychological state, level of independence and social relationship (13). Even slight changes of health state may result in worsening of social status and vice versa. Impaired social or financial situation usually has a great impact on health in this population group.

Our interviewers noted that the number of respondents rejecting the dispensation due to co-payment fluctuated during the study period and they suggest that it may depend on the length of time before or after they receive the income.

In our opinion, situation might be improved by introducing some instrument setting up the limit for individual participation for example in 12-month period as in Sweden (14) or excluding chronic and/or senior patients from financial participation, as it is in some other countries (15).

Our study demonstrates that there may be patients who may fail to gain access to medication due to co-payment. The financial participation on health care costs is generally low in the Czech Republic (8.8 \% of total health expenditures) but there were differences in co-payment levels in patients ranging from $1 \mathrm{CZK}$ to thousands CZK.

In our study co-payments were lower in very small communities, which may be due to better communication between physicians and patients or physicians and pharmacists and in the capital (which is most probably due to competition of pharmacies).

In the near future, private spending in health care might rise in the Czech Republic. The amendment of the Act on public health insurance in force from 2008 (16) introduces a fee for visiting a physician and fees for prescribed medicinal products in value of $30 \mathrm{CZK}$ each. To protect the patients from excessive costs, the amendment introduces a limit of co-payment in value of 5,000 CZK in one year.

Chronic medication is usually prescribed in three or six month interval. Respondents in our study used approx. 3.70 medicines. Their co-payment would increase due to fees upon approx. 111 CZK (123 or 105 CZK instead of 86 CZK) in four weeks. This would represent an increase of 140 or $120 \%$.
However, there is a need for future studies to analyse the exact impact of this new legislation on private spending in the Czech Republic.

In our study, we found a critical ethical problem in different levels of co-payment for concrete product. Although the range of all co-payments was within legal limits, differences show a possible adverse selection in less economically stable regions. In this way, citizens of the Czech Republic may fail to receive the health care under the same terms as declared by the constitution.

\section{Acknowledgement}

Authors would like to acknowledge the help of the Union of pensioners of the Czech Republic, which supported this study.

Authors would like to acknowledge the help of the staff of the Czech Statistical Office in providing information about the methodology of the data collection of the Office.

\section{REFERENCES}

1. Economic information on health care 2003. Prague: Institute of Health Information and Statistics of the Czech Republic; 2004.

2. Czech health statistics yearbook 2004. Prague: Institute of Health Information and Statistics of the Czech Republic; 2005.

3. Rokosová M, Háva P, Schreyögg J, Busse R. Health care systems in transition: Czech Republic. Copenhagen: WHO Regional Office for Europe on behalf of the European Observatory on Health Systems and Policies; 2005.

4. Organisation for Economic Co-operation and Development [homepage on the Internet]. OECD in figures - 2005 edition. Health spending and resources [cited 2006 Feb 5]. Available from: http://www.oecd.org/ document/62/0,3343,en_2649_34863_2345918_1_1_1_1,00.html.

5. Petrova GI. Monitoring of national drug policies - regional comparison between Bulgaria, Romania, Macedonia, Bosnia Herzegovina. Cent Eur J Public Health. 2001 Nov;9(4):205-13.

6. Czech health statistics yearbook 2003. Prague: Institute of Health Information and Statistics of the Czech Republic; 2004.

7. Money income, expenditure and consumption according to the Household Budget Survey 2004. Prague: Czech Statistical Office; 2005.

8. Public Health Insurance, as amended Act of 1997, Pub. L. No. 48/1997 Coll. Czech Republic (Mar 28, 1997). (In Czech.)

9. Code list of medicinal products: version 520/2004. Prague: General Health Insurance Fund of the Czech Republic; 2006. (In Czech.)

10. Health care in the Czech Republic in statistical data 2004. Prague: Institute of Health Information and Statistics of the Czech Republic; 2005.

11. World Health Organisation [homepage on the Internet]. Copenhagen: European health for all database [cited 2006 Feb 5]. Available from: http://data.euro.who.int/hfadb.

12. Decree of the Ministry of Health, which determines medicines fully reimbursed from public health insurance and the extent of reimbursement for particular medicinal substances Act of 1997, Pub. L. No. 57/1997 Coll. Czech Republic (Mar 28, 1997). (In Czech.)

13. Holčík J, Koupilová I. Defining and assessing health-related quality of life. Cent Eur J Public Health. 1999 Nov;7(4):207-9.

14. Pharmaceutical Benefits Act of 2003, Pub. L. No. SFS 2002:160. Sweden (Nov 4, 2003).

15. Busse R, Riesberg A. Health care systems in transition: Germany. Copenhagen: WHO Regional Office for Europe on behalf of the European Observatory on Health Systems and Policies; 2004.

16. Stabilisation of Public Budgets Act of 2007, Parliamentary draft No. 222/2007. Czech Republic (Aug 31, 2007). (In Czech.)

Received July 3, 2007 Accepted in revised form October 31, 2007 